\title{
Optimizing anticoagulant therapy in primary PCI for STEMI - time matters?
}

\author{
Vlad Bataila', Lucian Calmac', Alexandru Scafa Udriste',2, Diana Stanciulescu', Maria Dorobanu',2
}

\section{INTRODUCTION}

ST-elevation myocardial infarction is the most severe expression of coronary vascular disease with a great deal of burden on patients life expectancy but also on health systems. Much effort has been spent towards improving outcomes and because of that, its management has considerably evolved over the past decades. Nowadays, we have therapeutic protocols for both medical and interventional treatment that have been extensively studied and have significantly improved patients outcome. Reperfusion therapy is indicated in all STEMI patients with primary percutaneous coronary intervention $(\mathrm{PCl})$ as the preferred strategy. The aim of treatment is to establish myocardial reperfusion as soon as possible, therefore decreasing all patient related major outcomes. Current guidelines recommend that all patients undergoing primary $\mathrm{PCl}$ should receive double antiplatelet therapy (DAPT), aspirin and a $\mathrm{P}^{2} \mathrm{Y}_{12}$ inhibitor'. Regarding the anticoagulant therapy, guidelines recommend either unfractionated heparin (UFH) as the first choice, iv enoxaparin or bivalirudin I. Although the current guidelines clearly mention that the setting for the anticoagulant therapy should be cath lab related, very few information from the modern reperfusion era is available regarding the timing of administration, whether at first medical contact or in the cath lab. The current study attempts to evaluate the impact of early UHF administration along with double antiplatelet therapy on reperfusion parameters.

\section{OBJECTIVES}

We analyzed the impact of early unfractionated heparin administration along with DAPT in STEMI patients referred to primary $\mathrm{PCl}$ on coronary flow, myocardial perfusion, in-hospital major adverse clinical events (MACE) and major bleeding.

\section{MATERIALS AND METHODS}

This is an observational, retrospective, non-randomized study with subjects from a high volume primary $\mathrm{PCl}$ centre. The sample included patients with acute ST-segment elevation myocardial infarction admitted in our clinic in 2016, upon which an invasive coronary procedure was performed.

We selected the study patients by the following criteria:

- Inclusion criteria:

- Patients diagnosed with confirmed acute STsegment elevation myocardial infarction;

- Time from symptom onset to primary angioplasty not more than 24 hours;

- First acute coronary syndrome.

- Exclusion criteria:

- Administration of fibrinolytic therapy;

- History of acute coronary syndrome;

- Not STEMI diagnostic

- Time from symptom onset to primary angioplasty more than 24 hours;

- Insufficient data.

Data was gathered from the internal database of the cath lab as well as from the patients observation charts. We defined that the non-invasive reperfusion criterion was met if we identified the decrease of ST segment elevation by more than $50 \%$ between the electrocardiogram from the first medical contact and the one before the angiography.

\footnotetext{
' Emergency Clinical Hospital, Bucharest, Romania

${ }^{2}$,Carol Davila” University of Medicine and Pharmacy, Bucharest, Romania
}

$\checkmark$ Contact address:

Diana Stanciulescu, Emergency Clinical Hospital, Bucharest, Romania. 


\begin{tabular}{|c|c|c|c|}
\hline & $\begin{array}{c}\text { Lot } A \\
(n=128)\end{array}$ & $\begin{array}{c}\text { Lot } B \\
(n=148)\end{array}$ & $\mathbf{P}$ \\
\hline Age $m(\mathrm{IQR})$ & $60.8(21)$ & $59.1(23)$ & 0.39 \\
\hline Female. $n \%$ & $35(27.3 \%)$ & $49(32.9 \%)$ & 0.35 \\
\hline Smokers. n\% & $84(65.6 \%)$ & $89(60.1 \%)$ & 0.38 \\
\hline AHT. $n \%$ & $93(72.7 \%)$ & 115 (77.2\%) & 0.40 \\
\hline Dyslipidemia. $n \%$ & $76(59.5 \%)$ & $95(63.8 \%)$ & 0.46 \\
\hline DM. $n \%$ & $28(21.9 \%)$ & $39(26.2 \%)$ & 0.48 \\
\hline Stroke. $n \%$ & $9(7 \%)$ & $7(4.7 \%)$ & 0.70 \\
\hline History of angina. $n \%$ & $33(25.8 \%)$ & $49(32.9 \%)$ & 0.43 \\
\hline Severe valvulopathy. n\% & $5(3.9 \%)$ & $7(4.7 \%)$ & 0.82 \\
\hline $\mathrm{HR}>100$ bpm. $n \%$ & $15(12.5 \%)$ & $9(8.7 \%)$ & 0.39 \\
\hline SBP $<100 \mathrm{mmHg} . \mathrm{n} \%$ & $10(8.5 \%)$ & $6(6.5 \%)$ & 0.79 \\
\hline Anterior MI. n\% & $56(46.3 \%)$ & $35(36.5 \%)$ & 0.16 \\
\hline Killip class $>1 . n \%$ & $13(10.8 \%)$ & $26(11.9 \%)$ & 0.67 \\
\hline \multicolumn{4}{|l|}{ Pre-hospital medication } \\
\hline ASA. $n \%$ & $17(13.3 \%)$ & $24(22.1 \%)$ & 0.61 \\
\hline P2YI 2 inhibitors. $n \%$ & $3(2.3 \%)$ & $5(3.4 \%)$ & 0.73 \\
\hline Anticoagulation. $n \%$ & $\mathrm{I}(0.8 \%)$ & $9(6.0 \%)$ & 0.02 \\
\hline Beta-blocker. n\% & $21(16.4 \%)$ & $22(14.8 \%)$ & 0.74 \\
\hline Statin. $n \%$ & $17(13.3 \%)$ & $20(13.4 \%)$ & 0.99 \\
\hline
\end{tabular}

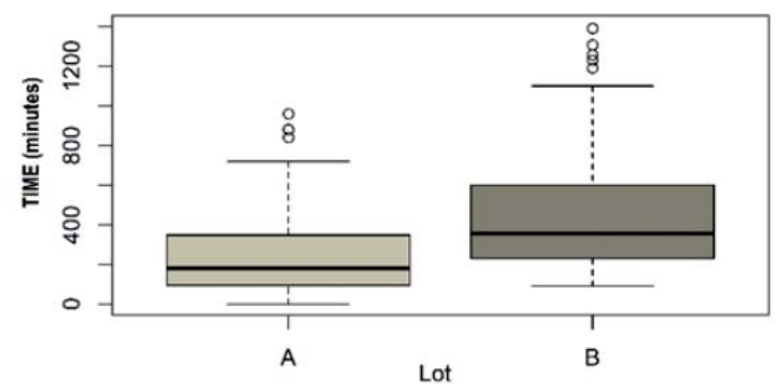

Figure I. Comparison between the time from syptom onset to antithrombotic treatment.

Regarding statistical analysis, categorical variables were presented as absolut values and percentages and were compared using chi-square test and continous variables were presented as averages and interquartile ranges and were compared using two tailed t-test or ANOVA. Also, when dealing with sparse data, we used Wilcoxon sum rank test and Fischer exact test. Finally, for categorical predictors, simple logistic regression and multivariate regression for adjustment for confounders were used. In all cases, a two sided $p$ value of 0.05 was used for significance.

\section{RESULTS}

The sample included 276 patients selected from 520 patients diagnosed with acute ST-segment elevation myocardial infarction, admitted directly to the Bucharest Emergency Clinical Hospital or transferred from another hospital for primary $\mathrm{PCl}$, that met the inclu-

\begin{tabular}{|c|c|c|c|}
\hline & $\begin{array}{c}\text { Lot } A \\
(n=128)\end{array}$ & $\begin{array}{c}\text { Lot } B \\
(n=\mid 48)\end{array}$ & $\mathbf{P}$ \\
\hline Clopidogrel loading dose. $n \%$ & $72(56.3 \%)$ & $55(36.9 \%)$ & 0.002 \\
\hline Ticagrelor loading dose. $n \%$ & $52(40.6 \%)$ & $28(18.8 \%)$ & $<0.001$ \\
\hline Ischaemic time. m minutes (IQR) & $546(364)$ & $357(276)$ & $<0.001$ \\
\hline Time to anticoagulation. $m$ minutes (IQR) & $476(335)$ & $315(245)$ & $<0.001$ \\
\hline Reperfusion criteria. $\mathrm{n} \%$ & $43(33.6 \%)$ & $15(10.1 \%)$ & $<0.001$ \\
\hline Coronary artery occlusion. $\mathrm{n} \%$ & $59(46.1 \%)$ & $59(39.6 \%)$ & 0.33 \\
\hline Min Hb. g/dl. (IQR) & $12.4(3)$ & $12.4(3)$ & 0.93 \\
\hline Death. $n \%$ & $8(6.2 \%)$ & $7(4.7 \%)$ & 0.16 \\
\hline
\end{tabular}




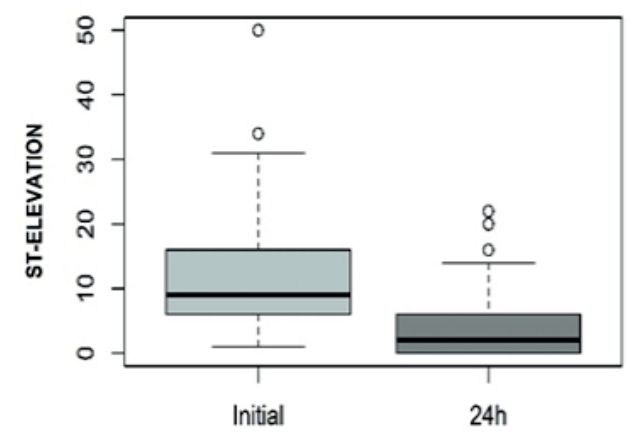

Group A

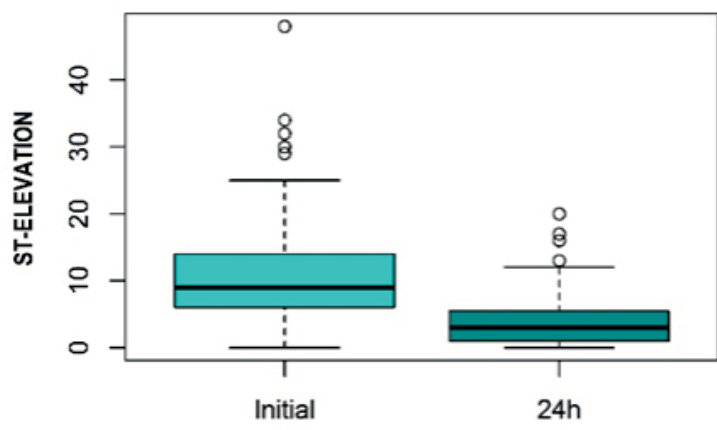

Group B

Figure 2. Comparison between ST-elevation at diagnosis vs. 24 hours after primary angioplasty.

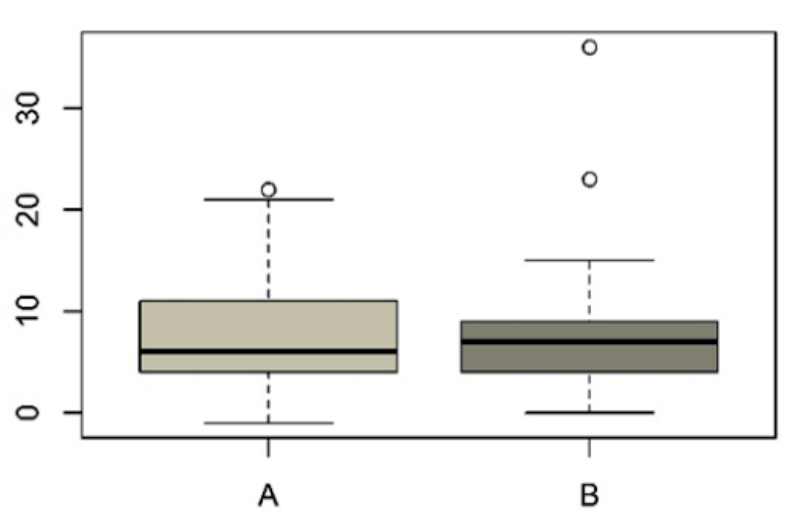

Figure 3. Comparison between ST-elevation depression lot A vs. lot B

sion criteria. The group of 278 subjects were divided into two lots (A and $B$ ) depending on the time of unfractionated heparin administration in relation to the coronary intervention procedure. Group $A$ is composed of 128 patients who received unfractionated heparin at the first medical contact and group $B$ consists of 148 patients who were delayed in the administration of unfractionated heparin, at the $\mathrm{PCl}$ centre.

There were less women, less hypertensives and less diabetics in Lot $\mathrm{A}$ but more smokers and patients with dyslipidemia. The lot A patients had worse vital signs but also were in a better Killip class at admission. Regarding the ongoing medication, there was a statistical significant difference in oral anticoagulation before the index event, with more patients receiving therapy in lot $B$. There were no statistically significant differences in characteristics between the 2 groups regarding baseline data, risk factors, and ongoing medication prior to the event (except for oral anticoagulation), thus inferring that the 2 groups are homogeneous (Table I).

Regarding the in-hospital management of the patients, we evaluated the double antiplatelet treatment, with significantly more patients receiving a loading dose of clopidogrel $(56.3 \%$ vs $36.9 \%, p=0.002)$ or ticagrelor $(40.6 \%$ vs $18.8 \% \mathrm{p}<0.00 \mathrm{I})$ in lot $\mathrm{A}$. The total ischaemic time was higher in lot $A$, with an average of 546 minutes vs $357 \mathrm{~min}, \mathrm{p}<0.00 \mathrm{I}$. Significantly more patients in group $A$ had reperfusion criteria $(33.6 \%$ vs $10.1 \%, p<0.001$ ) but there was only a trend for more patent coronary arteries in group A $(46.1 \%$ vs $39.6 \%$, $\mathrm{p}=\mathrm{NS})$. There were no statistical significant differences in minimal haemoglobin, ejection fraction or all cause death.

Regarding the moment of heparin administration after symptom onset, there are differences with statistical significance: group $A$ received HNF on average after 255.95 minutes, and group $B$ received the anti-

\begin{tabular}{|c|c|c|c|c|}
\hline \multirow{2}{*}{ Variables } & Univariate/independent & & Multivariate/adjusted & \\
\hline & O.R. ( $(95 \%$ C.I.) & P-value & O.R. (95\% C.I.) & P-value \\
\hline Age & $0.99(0.97-1.01)$ & 0.6 & $1.05(0.97-1.01)$ & 0.56 \\
\hline DM & $1.01(0.90-1.15)$ & 0.76 & $1.038(0.90-1.19)$ & 0.58 \\
\hline $\mathrm{AHT}$ & $0.54(0.29-1.02)$ & 0.06 & $0.61(0.29-1.25)$ & 0.18 \\
\hline Lot $A$ & $1.08(1.01-1.15)$ & 0.015 & $4.04(1.94-8.28)$ & $<0.001$ \\
\hline Ticagrelor loading dose & $1.53(0.83-2.84)$ & 0.16 & $1.16(0.59-2.32)$ & 0.65 \\
\hline Ischaemic time (h) & $1.08(1.02-1.14)$ & 0.003 & $\mathrm{I} .05(0.99-\mathrm{I} . \mathrm{II})$ & 0.09 \\
\hline
\end{tabular}


coagulant on average after 346.5 I minutes (Figure I). Group B received the UFH approximately 90 minutes later than group $A$ with statistically significant differences $(p=0.0054)$.

Analysis of electrocardiographic changes by ST elevation sum from diagnosis and 24 hours after $\mathrm{PCl}$ was performed. For group $A$ the average of ST segment elevation amplitude at first medical contact is 11.85 $\mathrm{mm}$ and 24 hours after angioplasty is $3.98 \mathrm{~mm}$. The ST-segment elevation decreases on average by 7.87 $\mathrm{mm}(\mathrm{p}<0.0 \mathrm{l})$. For group $B$ the average is $11.12 \mathrm{~mm}$ and 24 hours after is $3.76 \mathrm{~mm}$, the ST segment elevation decreasing on average by $7.36(p<0.05)$ (Figure 2). Both study groups showed signs of myocardial reperfusion 24 hours after $\mathrm{PCl}$. There were no significant differences regarding the evolution of the electrocardiographic aspect between the study groups at 24 hours after $\mathrm{PCl}$ (Figure 3).

Following a binomial univariate logistic regression performed in order to evaluate spontaneous reperfusion, numerous predictors were identified, with ischaemic time and early administration of heparin being statistically significant. The lack of arterial hypertension and ticagrelor loading dose almost achieved significance. After adjusting for confounders, only early administration heparin was identified as independent predictor (O.R. 4.04; C.I. I.94-8.28) and also ischaemic time measured in hours (O.R. I.05; $95 \% \mathrm{Cl} 0.99$ - I.II) was close to reach significance (Table 3).

TIMI flow 3 was obtained in the large majority of the patients, with only 4 patients, two in each group with coronary TIMI flow 2. Eptifibatide was administered intraprocedurally, with a single dose as bailout, with no significant difference between groups (16.96\% vs $15.66 \%, p-N S)$.

There were only two major bleeding events requiring transfusion and a similar average lowest haemoglobin between groups. Global all-cause in-hospital mortality was $5.4 \%$. There were more patients that died in group $A$ than $B(6.2 \%$ vs $4.7 \%$; $p$ NS).

\section{DISCUSSIONS}

STEMI is one of the leading morbi-mortality causes in modern times. It has an extremely high social, logistic and financial burden on all healthcare services from the primary sector to the tertiary care centers. Nowadays, primary PCl is the cornerstone in STEMI treatment. A well defined pipeline of actions was established in pre-hospital as well as in-hospital care in order to lower the ischaemic time as much as possible ${ }^{1-4}$.
The antithrombotic therapy is the mainstay of the pharmacological treatment in STEMI. In present primary $\mathrm{PCl}$ era, the antiplatelet and anticoagulant therapies have an adjunctive role. They are used for preventing stent thrombosis and vessel reocclusion and to prevent blod clot formation on the devices used during primary $\mathrm{PCl}$.

Medical practice guidelines today have very specific recommendations regarding the antithrombotic regimen in STEMI. Both antiplatelets, aspirin and a $\mathrm{P} \mathrm{Y}_{12}$ inhibitor have a class I recommendation and it is also mentioned that should be administered as soon as possible in patients with STEMI that undergo primary $\mathrm{PCl}^{1-4}$. Regarding only to $\mathrm{P}_{2} \mathrm{Y}_{12}$ inhibitors, it was demonstrated that clopidogrel given in loading dose as soon as possible is superior to in-cath lab administration $^{5}$. On the other hand, early administration of ticagrelor failed to improve patients outcome compared to in-catheterization laboratory treatment in two large trials ${ }^{6,7}$.

The medical guidelines recommend heparin as first choice of anticoagulation treatment in STEMI in patients undergoing primary $\mathrm{PCl}^{\prime}$. It is widely used in Europe and there is good experience with it in the cath lab, and its action can be monitored by the activating clotting time. Although the adjunctive effect in coronary reperfusion is supported by the pharmacodynamics of heparin, this was not researched in modern clinical trials. An older, non-randomized, not controlled trial, showed that high dose heparin (300U/ $\mathrm{kg}$ ) led to better coronary reperfusion ${ }^{8}$. Current guidelines do not support or even mention the use of heparin outside the cath-lab and fibrinolytic therapies ${ }^{2,19}$, although up-stream use of heparin in patients that will undergo primary $\mathrm{PCl}$ is reported by some centres ${ }^{\prime \prime}$.

The cornerstone of STEMI treatment is the re-establishment of coronary flow with the more important consequence of eliminating the myocardial ischaemia. This is performed either pharmacological or interventional, but in $7-27 \%$ of patients this happens spontaneously before the standard reperfusion therapy, usually with a very good outcome ${ }^{12,13}$. Spontaneous oronary reperfusion (SR) is also accompanied by a significantly easier $\mathrm{PCl}$ procedure. As the administration of heparin during primary $\mathrm{PCl}$ is the standard of care, a question arises regarding the benefits of up-stream use of heparin in STEMI patients that will undergo primary $\mathrm{PCl}$ compared to the standard cath-lab administration.

The present study aims to present the effect of antithrombotic therapy and its timing in real-life patients from a registry in a high volume $\mathrm{PPCl}$ centre. The sig- 
nificant difference between groups regarding oral anticoagulation between groups can be explained by the restraint of administering heparin in that group. The most important result was the presence of non-invasive reperfusion criteria, with significant more cases of ST segment resolution in lot $A$. The resolution of the ST segment during STEMI is correlated with a lesser degree of microvascular disfunction and a lower morbidity and mortality with better outcomes ${ }^{14,15}$. Although there was only a statistical trend, there were more cases of patent cuplrit artery in lot A. Older studies that evaluated facilitated reperfuson with trombolytics or GPIlbIlla inhibitors had as primary endpoints a patent STEMI culprit artery at invasive evaluation, but with no difference in clinical outcomes, although some trials had patency rates as high as $61 \%^{16}$. On the other, SR was associated with significant better outcomes ${ }^{17}$.

Also, it is important to take notice of the significantly more patients being treated early with double antiplatelet in the first group. This is possibly explained by the fact that the whole antithrombotic regimen, both antiplatelet and anticoagulant, is usually administered in the first medical contact centre. Therefore this could partially explain the effect on spontaneous reperfusion in this study, although the multivariate adjusted regression analysis showed that only early heparin was associated with reperfusion. It is worth mentioning that in this study, one might describe the SR as facilitated reperfusion. This term was historically associated with routine upstream administration of Gpllbllla inhibitors or trombolytics either in full or in half dose before primary $\mathrm{PCl}$. These studies did not show net clinical benefits and also increased the bleeding risk ${ }^{18-20}$. In present days there is no indication for facilitated reperfusion. Having in mind that the entire STEMI treatment management should consist of a concerted action between the antithrombotic and antiischemic medication on one hand and the invasive act on the other hand, we could name it a pharmacoinvasive approach.

Long ischaemia times have a significant impact on the entire STEMI treatment paradigm with worse outcomes $^{21}$. On the other hand, in this study, the significance of ischaemia time comes from the longer transfer time in lot $A$ ( 90 min. on average) that could lead to more time for the antithrombotic medication to act and as a consequence to increase the reperfusion rate. Longer ischaemia time in lot $A$ could also come from selection bias. A cornerstone trial regarding primary $\mathrm{PCl}$ network showed that transfer from $120 \mathrm{~km}$ and a delay of 60 minutes are tolerable and with good out- come. In this trial, after transfer and antithrombotic therapy, there was a patent artery rate of $31 \%{ }^{22}$ It is worth mentioning that there is still a high percentage of patients in Romania that do not receive thrombolytic therapy despite guideline indication ${ }^{23,24}$. In this light, there is even more potential benefit of complete antithrombotic treatment at first medical contact. The administration of heparin at first medical contact was shown to be safe, with no additional risk of bleeding. There was a higher percentage of patient deaths in lot $A$, possibly cause by a longer ischaemia time and a low patient number included.

\section{CONCLUSIONS}

The management and network of STEMI is one of the most well defined in today's health systems. Although the related morbidity and mortality has been decreasing since the implementation of STEMI programs, it still represents a significant burden on people and healthcare systems, especially in countries or regions with suboptimal resources. The present study reflects the reality of Romania's STEMI network, with long ischemia times and patients receiving incomplete premedication. Its results are hampered by a lack of randomization and by a low number of patients. A new registry type study, with a much larger number of consecutive patients, that could shed more light on the effect of heparin on reperfusion at first medical contact, is on the way.

\section{Conflict of interest: none declared.}

\section{References}

I. Ibanez B, James S, Agewall S, Antunes MJ, Bucciarelli-Ducci C, Bueno $\mathrm{H}$, et al. 2017 ESC Guidelines for the management of acute myocardial infarction in patients presenting with ST-segment elevation: The Task Force for the management of acute myocardial infarction in patients presenting with ST-segment elevation of the European Socie. Eur Heart J [Internet]. 2017 Aug 26;39(2):I 19-77. Available from: https://doi.org/10.1093/eurheartj/eh×393

2. Neumann F-J, Sousa-Uva M, Ahlsson A, Alfonso F, Banning AP, Benedetto $U$, et al. 2018 ESC/EACTS Guidelines on myocardial revascularization. Eur Heart J [Internet]. 2018 Aug 25;40(2):87-165. Available from: https://doi.org/10.1093/eurheartj/ehy394

3. Antman EM, Anbe DT, Armstrong PW, Bates ER, Green LA, Hand $M$, et al. ACC / AHA PRACTICE GUIDELINES - FULL TEXT ACC I AHA Guidelines for the Management of Patients With ST-Elevation Myocardial Infarction A Report of the American College of Cardiology / American Heart Association Task Force on. 2004;6083.

4. O'Gara PT, Kushner FG, Ascheim DD, Casey DE, Chung MK, de Lemos JA, et al. 2013 ACCF/AHA Guideline for the Management of ST-Elevation Myocardial Infarction. Circulation [Internet]. 2013 Jan 29 [cited 2019 Sep 5]; I27(4). Available from: https://www.ahajournals.org/doi/I0.1 I6I/CIR.0b0I3e3182742cf6

5. Koul S, Smith JG, Schersten F, James S, Lagerqvist B, Erlinge D. Effect of upstream clopidogrel treatment in patients with ST-segment elevation myocardial infarction undergoing primary percutaneous coronary intervention. Eur Heart J. 20I I Dec;32(23):2989-97. 
6. Montalescot G, van 't Hof AW, Lapostolle F, Silvain J, Lassen JF, Bolognese L, et al. Prehospital Ticagrelor in ST-Segment Elevation Myocardial Infarction. N Engl J Med [Internet]. 20I4 Sep I;37I (I I): 101627. Available from: https://doi.org// 0.1056/NEJMoal 407024

7. Koul S, Smith JG, Götberg M, Omerovic E, Alfredsson J, Venetsanos $D$, et al. No Benefit of Ticagrelor Pretreatment Compared With Treatment During Percutaneous Coronary Intervention in Patients With ST-Segment-Elevation Myocardial Infarction Undergoing Primary Percutaneous Coronary Intervention. Circ Cardiovasc Interv [Internet]. 2018 Mar [cited 2019 Sep 5]; I (3):e005528. Available from: https://www.ahajournals.org/doi//0.1 I6I/CIRCINTERVENTIONS.117.005528

8. Verheugt FW, Liem A, Zijlstra F, Marsh RC, Veen G, Bronzwaer JG. High dose bolus heparin as initial therapy before primary angioplasty for acute myocardial infarction: results of the Heparin in Early Patency (HEAP) pilot study. J Am Coll Cardiol [Internet]. 1998 Feb [cited $2020 \mathrm{Apr} 7] ; 3$ I(2):289-93. Available from: http://www.ncbi.nlm.nih. gov/pubmed/9462569

9. Ibanez B, James S, Agewall S, Antunes MJ, Bucciarelli-Ducci C, Bueno $\mathrm{H}$, et al. 2017 ESC Guidelines for the management of acute myocardial infarction in patients presenting with ST-segment elevation. Eur Heart J. 2018;39(2): 119-77.

10. Rich MW, Louis S. Heparin for Acute Myocardial Infarction: The Controversy Continues* [Internet]. 1998 [cited 2019 Sep 5]. Available from: http://www.onlinejacc.org/content/accj/3I/5/964.full.pdf

II. Hermanides RS, Kilic S, van't Hof AWJ. Optimal pharmacological therapy in ST-elevation myocardial infarction-a review: A review of antithrombotic therapies in STEMI. Netherlands Hear J. 2018; 26(6):296-310.

12. Stone GW, Cox D, Garcia E, Brodie BR, Morice MC, Griffin J, et al. Normal flow (TIMI-3) before mechanical reperfusion therapy is an independent determinant of survival in acute myocardial infarction: Analysis from the Primary Angioplasty in Myocardial Infarction Trials. Circulation [Internet]. 200 I Aug 7 [cited 2020 Apr 7]; 104(6):6364I. Available from: http://www.ncbi.nlm.nih.gov/pubmed/I I489767

13. Uriel N, Moravsky G, Blatt A, Tourovski A, Gabara Z, Inna Y, et al. Acute myocardial infarction with spontaneous reperfusion: clinical characteristics and optimal timing for revascularization. Isr Med Assoc J [Internet]. 2007 Apr [cited 2019 Sep 5];9(4):243-6. Available from: http://www.ncbi.nlm.nih.gov/pubmed/I749/2/4

14. Kim BG, Cho SW, Ha J-H, Ahn HS, Lee HY, Kim GS, et al. Relationship between the ST-Segment Resolution and Microvascular Dysfunction in Patients Who Underwent Primary Percutaneous Coronary Intervention. Cardiol Res Pract. 2019;2019.

15. de Waha S, Patel MR, Granger CB, Ohman EM, Maehara A, Eitel I, et al. Relationship between microvascular obstruction and adverse events following primary percutaneous coronary intervention for ST-segment elevation myocardial infarction: an individual patient data pooled analysis from seven randomized trials. Eur Heart J [Internet] 2017 Dec 14 [cited 2019 Dec 7];38(47):3502-10. Available from: http://academic.oup.com/eurhearti/article/38/47/3502/4055902

16. Ross AM, Coyne KS, Reiner JS, Greenhouse SW, Fink C, Frey A, et al. A randomized trial comparing primary angioplasty with a strategy of short-acting thrombolysis and immediate planned rescue angioplasty in acute myocardial infarction: The PACT trial. J Am Coll Cardiol. 1999 Dec;34(7): 1954-62.

17. Brodie BR, Stuckey TD, Hansen C, Muncy D. Benefit of coronary reperfusion before intervention on outcomes after primary angioplasty for acute myocardial infarction. Am J Cardiol [Internet]. 2000 Jan I [cited 2020 Apr 7];85(I):I3-8. Available from: http://www.ncbi.nlm. nih.gov/pubmed/I 1078229

18. Ellis SG, Tendera M, de Belder MA, van Boven AJ, Widimsky P, Janssens $\mathrm{L}$, et al. Facilitated $\mathrm{PCl}$ in Patients with ST-Elevation Myocardial Infarction. N Engl J Med [Internet]. 2008 May 22 [cited 2019 Sep 14];358(21):2205-17. Available from: http://www.nejm.org/doi/ abs/I0.1056/NEJMoa07068I6

19. O'Gara PT, Kushner FG, Ascheim DD, Casey DE, Chung MK, De Lemos JA, et al. 20I3 ACCF/AHA guideline for the management of st-elevation myocardial infarction: Executive summary: A report of the American college of cardiology foundation/american heart association task force on practice guidelines. J Am Coll Cardiol. 2013; 6I(4):485-5I0.

20. Members AF, Steg PG, James SK, Atar D, Badano LP, Lundqvist CB, et al. ESC Guidelines for the management of acute myocardial infarction in patients presenting with ST-segment elevation: The Task Force on the management of ST-segment elevation acute myocardial infarction of the European Society of Cardiology (ESC). Eur Heart J [Internet]. 2012 Aug 24;33(20):2569-619. Available from: https:// doi.org/10.1093/eurheartj/ehs215

21. Antman EM. Time Is Muscle. Translation Into Practice. Vol. 52, Journal of the American College of Cardiology. 2008. p. 1216-21.

22. Widimský P. Long distance transport for primary angioplasty vs immediate thrombolysis in acute myocardial infarction Final results of the randomized national multicentre trial-PRAGUE-2. Eur Heart J [Internet]. 2003 Jan I [cited 2020 Apr 7];24(I):94-104. Available from: https://academic.oup.com/eurheartj/article-lookup/ doi/I0.1016/S0195-668X(02)00468-2

23. Dorobanțu $M$, Câlmâc L, Bogdan A, Bataila $V$, Dragoescu B, Radu $A$, et al. Particularities in coronary revascularization in elderly patients presenting with ST segment elevation acute myocardial infarction (STEMI). Vol. 56, Cor et Vasa. Elsevier Science B.V.; 20I4. p. e342-7.

24. Calmac L, Bataila V, Ricci B, Vasiljevic Z, Kedev S, Gustiene O, et al. Factors associated with use of percutaneous coronary intervention among elderly patients presenting with ST segment elevation acute myocardial infarction (STEMI): Results from the ISACS-TC registry. Int J Cardiol [Internet]. 2016 Aug I [cited 2020 Mar 23];217:S2 I-6. Available from: http://www.ncbi.nlm.nih.gov/pubmed/2738I859. 